${ }^{1}$ Graduate Program in Clinical Dentistry. Universidade Positivo. Curitiba, Paraná, Brazil.

${ }^{2}$ Department of Stomatology Universidade Federal do Paraná. Curitiba, Paraná, Brazil.
Corresponding author: Melissa Rodrigues de Araujo Address: Rua Francisco Juglair 749 Mossungue. Curitiba - Paraná. Brazil. Zip code: $81200-230$ Phone number: +55 4133604050 Email: melissararaujo@ufpr.br (iD) https://orcid.org/0000-0002-2180-8223

Conflict of interest statement: All authors declare that there are no conflicts of interest.

Received: April 24, 2019

Accepted: August 232019

\section{Impact of oral medicine training on oral cancer-related knowledge among undergraduate dental students}

\author{
Gisele Reisdoerfer ${ }^{1}$, Gilmar José Begnini', Flares \\ Baratto-Filho ${ }^{1}$, Juliana Feltrin de Souza ${ }^{2}$, Carla \\ Castiglia Gonzaga ${ }^{1}$, Melissa Rodrigues de Araujo ${ }^{1, *}$
}

Aim: The aim of this study was to evaluate knowledge and attitudes regarding potentially malignant oral lesions and oral cancer among undergraduate dental students with or without training in the oral medicine. Methods: A cross-sectional study was undertaken to assess all undergraduate dental student (1st to 5th year) in two private universities in the state of Paraná, Brazil. A structured questionnaire about knowledge regarding potentially malignant oral lesions, continuing education, and different approaches to diagnosis was administered to dental students with or without training in the oral medicine discipline between May and July 2015. Descriptive statistics were obtained, and the data were analyzed using a chi-square test to compare knowledge in dental students. Results: A total of 662 undergraduate dental students were invited to participate, and the response rate was $97.6 \%(n=646)$. Of the responders, 472 were female (73.1\%), 168 were male (26.0\%), and 6 did not declare what sex they were $(0.9 \%)$. Undergraduate dental students who had previously studied oral medicine tended to report that they always perform complete intraoral examination (76.3\%) and identified alcohol (87\%) and tobacco consumption (97\%) and sun exposure (80\%) as major risk factors for developing oral cancer. While students who had not yet studied oral medicine poorly identified these factors. Students who had previously studied the discipline did not identify cheilitis actinica (26\%) and erythroplakia (32\%) as potentially malignant lesions. Only, 32.6\% of dental students participate in continuing education during the past year. Conclusions: Dental students trained in the oral medicine discipline exhibited satisfactory knowledge necessary for the prevention and early identification of potentially malignant oral lesions and oral cancer. Continuing education during undergraduate and after academic training is very important.

Keywords: Students, dental. Knowledge. Mouth neoplasms. Oral medicine. 


\section{Introduction}

Head and neck cancers are currently the seventh most commonly diagnosed types of cancers in the world, and two-thirds of cases occur in men. They account for $2.1 \%$ of cancers worldwide and $1.8 \%$ of deaths, $77 \%$ of which occur in less-developed regions ${ }^{1}$. Tobacco and alcohol consumption are independently associated with increased risks of head and neck cancer. When combined these factors have synergistic effects, increasing the risk of developing a malignant oral neoplasm². The likelihood of developing squamous cell carcinoma (SCC), which accounts for $90 \%$ of all oral cancers ${ }^{3}$, can be reduced by $30 \%$ via smoking cessation ${ }^{2}$. Other recognised risk factors include human papillomavirus (HPV), which is associated with oropharyngeal cancer onset, older age, immunosuppression, and low fruit and vegetable intake ${ }^{4}$. Notably however, community knowledge pertaining to the risk factors and early signs and symptoms of oral cancer is unclear and evidently insufficient ${ }^{5}$.

Most cases of oral cancer are diagnosed in the advanced stages ${ }^{6}$. Community awareness regarding the onset of the first signs and symptoms of oral cancer, as well as the education of health professionals, are directly associated with early diagnosis, reduction of morbidities related to treatment, and increased cure rates ${ }^{3}$. Dentists play a fundamental role in the primary prevention of oral cancer by informing their patients about the importance of avoiding the major risk factors ${ }^{5}$, detecting early potentially malignant lesions ${ }^{7}$ (PMLs), and performing routine systematic examination of the oral mucosa².

The average level of oral cancer knowledge possessed by dentists is insufficient, and the subject is reportedly not well understood by undergraduate students ${ }^{8}$. This suggests a need for more structured academic programs, which would result in improved professional skills and abilities ${ }^{9}$. The aim of the current study was to evaluate knowledge and attitudes about PMLs and oral cancer in undergraduate dental students with and without training in oral medicine.

\section{Materials and methods}

This cross-sectional study was based on a survey administered to undergraduate dental students in two dental schools. The Research Ethics Committee of the University of Positivo, Brazil (protocol number 45245615.0.0000.0093), approved the study. The sample comprised 662 undergraduate dental students ranging from 1st year to 5th year derived the Schools of Dentistry of two institutions in Paraná, Brazil, the University of Positivo (4th and 5th-year undergraduates) and União de Ensino do Sudoeste do Paraná (Unisep) (5th-year undergraduates) from May to July in 2015. The sample was divided into students who had not received information about oral cancer or completed an Oral Medicine course (i.e. 1st and 2nd-year students) and those who had completed an Oral Medicine course (i.e. 3rd, 4th and 5th-year students).

As inclusion criteria students were required to be regularly enrolled in the Dentistry course, and present at the time the survey was administered. Participation was voluntary, and participants were informed that their responses would remain anonymous and confidential. All participants provided written informed consent. All data obtained 
in the study were self-reported based-paper questionnaire. Two researchers were involved, and a pilot study and calibration were conducted with 10 students in order to obtain the average time needed to answer the questionnaire and sign the informed consent term.

The research tool was a questionnaire comprising 19 closed questions adapted from those developed by Andrade et al. ${ }^{10}$ and Angheben et al. ${ }^{11}$. The questions pertained to sociodemographic variables including sex, age and graduation year, and knowledge about PMLs and the initial stages of malignancy, as well as knowledge about other aspects of oral cancer including clinical signs, common histological types, risk factors, age effects, commonly involved anatomical sites, and relevant diagnostic tools. Risk factors for oral cancer were determined based on the literature ${ }^{12,13}$. Knowledge about oral precursor lesions was evaluated with reference to classifications proposed by Warnakulasuriya et al. ${ }^{14}$ in 2007 and the World Health Organization ${ }^{15}$ in 2017.

Statistical analysis was performed using the Statistical Package for Social Sciences ${ }^{\circ}$ program (SPSS version 20.0; SPSS Inc., Chicago, IL, USA). Descriptive statistics were obtained and described, when appropriate, as absolute (n) and relative frequencies $(\%)$, and means and standard deviations (SD).

Chi-square tests were used to determine if there is a significant relationship between two nominal (categorical) variables. In the present study, the two variables were the questions included in the questionnaire and whether the undergraduate student had completed an Oral Medicine course. The frequency of each category for one nominal variable was compared across the categories of the second nominal variable. The data was presented in contingency tables (Tables 2 , 3 and 4) where the rows represent a category for one variable and columns represent a category for the other variable. Chi-square tests were performed with a significance level of $5 \%(p<0.05)$.

\section{Results}

A total of 662 undergraduate dental students were invited to participate, and the response rate was $97.6 \%(n=646)$. Of the responders, 472 were female $(73.1 \%), 168$ were male (26.0\%), and 6 did not declare what sex they were $(0.9 \%)$. The mean age was 22.1 years (SD 4.9 years). A total of 290 students (44.9\%) had studied oral medicine, whereas 356 (55.1\%) had not (Table 1).

Table 1. Demographics of the study population (N=646; Paraná, Brazil).

\begin{tabular}{lcc}
\hline Variables & \multicolumn{1}{c}{$\mathbf{n}(\%)$} \\
\hline \multirow{2}{*}{ Sex } & Female & $472(73.1)$ \\
\cline { 2 - 3 } & Male & $168(26.0)$ \\
\cline { 2 - 3 } Age (mean SD) & No response & $6(0.9)$ \\
\hline \multirow{2}{*}{ Studied oral medicine } & & $22.1 \pm 4.9$ \\
\cline { 2 - 3 } & Yes & $290(44.9)$ \\
\hline
\end{tabular}

Abbreviations: SD, standard deviation. 
Levels of knowledge pertaining to complete clinical examinations and palpation of the ganglionic chains in the head and neck region were used to evaluate perceptions and capacity for the detection of oral cancer signs and symptoms, and how the students would proceed if the diagnoses were confirmed (Table 2). Levels of knowledge about risk factors for oral cancer were evaluated, and the data are summarised in Figure 1. There was a difference for the risk factors: alcohol, tobacco, sun exposure

Table 2. Undergraduate dental students' attitudes regarding oral cancer prevention ( $N=646$; Paraná, Brazil).

\begin{tabular}{|c|c|c|c|c|}
\hline \multirow[b]{2}{*}{ Questions } & & \multicolumn{2}{|c|}{ Oral medicine course } & \multirow[b]{2}{*}{$\mathrm{p}$-value } \\
\hline & & $\begin{array}{c}\text { Yes } \\
\mathrm{n}(\%)\end{array}$ & $\begin{array}{c}\text { No } \\
n(\%)\end{array}$ & \\
\hline \multirow{6}{*}{$\begin{array}{l}\text { Do you submit the patient } \\
\text { to a complete intraoral } \\
\text { examination during the } \\
\text { first consultation? } \\
n=592\end{array}$} & $\mathrm{n}$ & 287 & 305 & \multirow{6}{*}{$<0.001$} \\
\hline & Always & $219(76.3)$ & $137(44.9)$ & \\
\hline & Usually & $40(13.9)$ & $44(14.4)$ & \\
\hline & Sometimes & $22(7.6)$ & $27(8.8)$ & \\
\hline & Rarely & $6(2.09)$ & $13(4.2)$ & \\
\hline & Never & $0(0.0)$ & $84(27.5)$ & \\
\hline \multirow{6}{*}{$\begin{array}{l}\text { Do you performs lymph } \\
\text { node palpation during the } \\
\text { first appointment? } \\
n=587\end{array}$} & $n$ & 286 & 301 & \multirow{6}{*}{$<0.001$} \\
\hline & Always & $160(55.9)$ & $72(23.9)$ & \\
\hline & Usually & $52(18.1)$ & $51(16.9)$ & \\
\hline & Sometimes & $55(19.2)$ & $44(14.6)$ & \\
\hline & Rarely & $13(4.5)$ & $29(9.6)$ & \\
\hline & Never & $6(2.1)$ & $105(34.8)$ & \\
\hline \multirow{6}{*}{$\begin{array}{l}\text { What is your reason for } \\
\text { not completing a complete } \\
\text { physical examination? } \\
n=151\end{array}$} & $n$ & 19 & 132 & \\
\hline & $\begin{array}{l}\text { Does not know how to perform } \\
\text { a clinical examination and } \\
\text { palpation. }\end{array}$ & $5(26.3)$ & $64(48.4)$ & $<0.001$ \\
\hline & $\begin{array}{c}\text { Does not know how to perform } \\
\text { a clinical examination. }\end{array}$ & $0(0.0)$ & 19 (14.3) & $<0.001$ \\
\hline & Does not know how to palpate. & $12(63.1)$ & $35(26.5)$ & $<0.001$ \\
\hline & Does not have enough time. & $1(5.2)$ & $8(6.1)$ & $<0.001$ \\
\hline & Does not find it important. & $1(5.2)$ & $6(4.5)$ & $<0.001$ \\
\hline \multirow{3}{*}{$\begin{array}{l}\text { Have you previously } \\
\text { detected a malignant } \\
\text { lesion? } \\
n=572\end{array}$} & $n$ & 279 & 293 & \multirow{3}{*}{0.009} \\
\hline & Yes & $20(7.1)$ & $7(2.3)$ & \\
\hline & No & $259(92.8)$ & $286(97.6)$ & \\
\hline \multirow{7}{*}{$\begin{array}{l}\text { If you find oral lesions } \\
\text { suspected to be } \\
\text { malignant, how would you } \\
\text { proceed? } \\
\mathrm{n}=582\end{array}$} & $\mathrm{n}$ & 281 & 301 & \\
\hline & Perform diagnostic procedures. & $18(6.4)$ & $7(2.3)$ & 0.023 \\
\hline & $\begin{array}{c}\text { Refer to an oral medicine } \\
\text { specialist. }\end{array}$ & $125(44.9)$ & $90(29.9)$ & $<0.001$ \\
\hline & Refer to a physician. & $8(2.8)$ & $25(8.3)$ & 0.006 \\
\hline & $\begin{array}{l}\text { Refer to the Faculty of } \\
\text { Dentistry. }\end{array}$ & $23(8.9)$ & $12(4.0)$ & 0.037 \\
\hline & Refer to a specialized hospital. & $15(5.3)$ & $24(7.8)$ & 0.246 \\
\hline & $\begin{array}{l}\text { Wait for manifestation of the } \\
\text { patient. }\end{array}$ & $0(0.0)$ & $2(0.7)$ & 0.5 \\
\hline
\end{tabular}

Note: Chi square test. Significance level of 0.05 . In each question, missing values correspond to non-response. 
and HPV infection $(p<0.001)$. Levels of knowledge pertaining to PMLs are represented in Figure 2. Leucoplakia was identified as a PML by $73 \%$ students who had previously studied oral medicine, while only $46 \%$ of students who had not yet studied oral medicine identified it. Other PMLs such as erythroplakia, lichen planus, and actinic cheilitis were only correctly identified by approximately $30 \%$ of students who had studied oral medicine and $10 \%$ of students who had not.

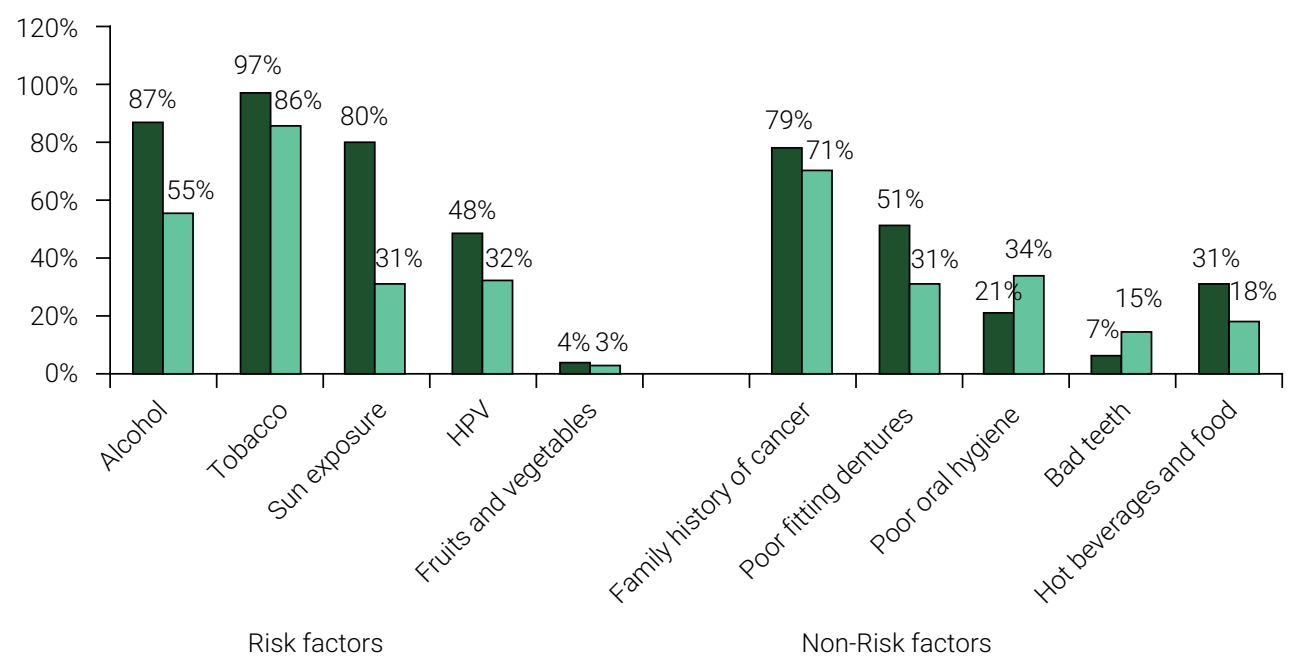

Oral medicine course

$\square$ No oral medicine course

Figure 1. Risk factors and non-risk factors for oral cancer identified by students who had completed training in oral medicine and those who were yet to undergo training in this discipline. HPV: human papillomavirus

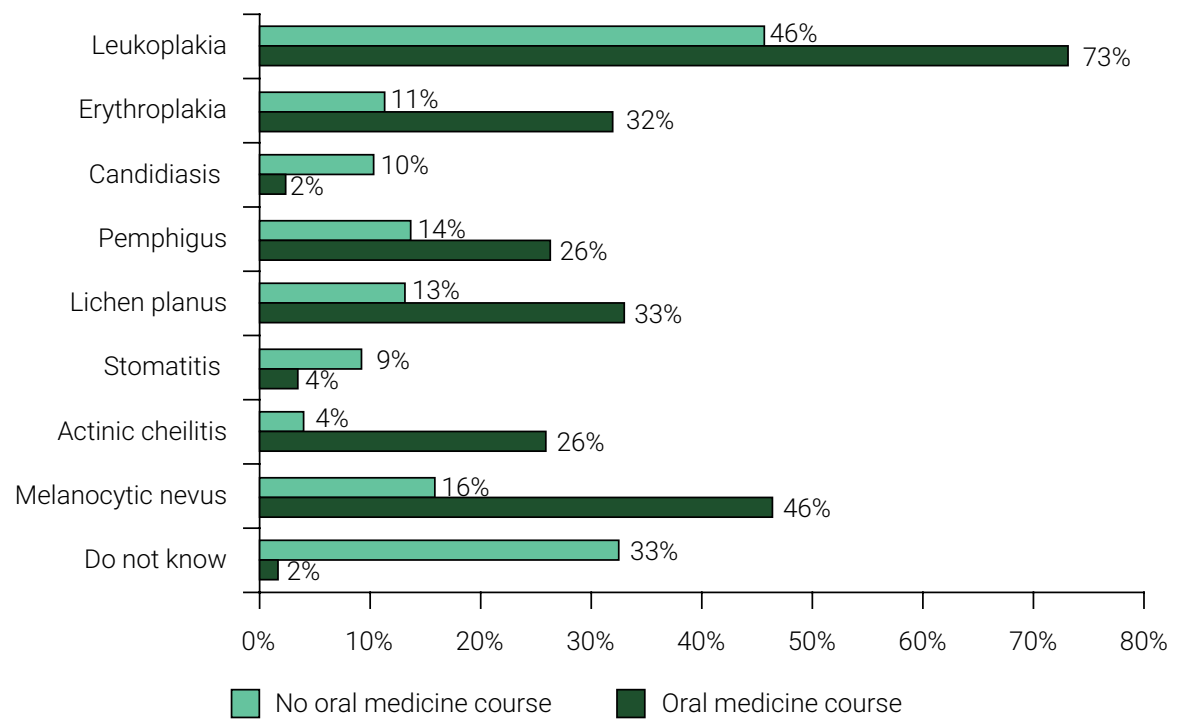

Figure 2. Percentage of students who correctly identified potentially malignant lesions, according to whether they had completed the oral medicine course. 
The students' knowledge about oral cancer is summarised in Table 3. The majority of students were evidently aware that the prevalence of oral cancer is higher in people aged 40 years and over, and awareness of this was higher in students who had studied oral medicine. The majority of respondents correctly identified SCC as the most common histological type of oral cancer, and again awareness of this was higher in students who had studied oral medicine.

Table 3. Undergraduate Dental students' knowledge regarding oral cancer ( $N=646$; Paraná, Brazil).

\begin{tabular}{|c|c|c|c|c|}
\hline \multirow[b]{2}{*}{ Questions } & & \multicolumn{2}{|c|}{ Oral medicine course } & \multirow[b]{2}{*}{$\mathrm{p}$-value } \\
\hline & & $\begin{array}{l}\text { Yes } \\
\mathrm{n}(\%)\end{array}$ & $\begin{array}{c}\text { No } \\
n(\%)\end{array}$ & \\
\hline \multirow{5}{*}{$\begin{array}{l}\text { What is the most common } \\
\text { age group in which oral } \\
\text { cancer is found? } \\
n=625\end{array}$} & $\mathrm{n}$ & 283 & 342 & \multirow{5}{*}{$<0.001$} \\
\hline & $<18$ years & $0(0.0)$ & $2(0.6)$ & \\
\hline & $18-39$ years & $46(16.3)$ & $86(25.1)$ & \\
\hline & $>40$ years & $230(81.3)$ & $185(54.1)$ & \\
\hline & Do not know. & $7(2.5)$ & $69(20.2)$ & \\
\hline \multirow{4}{*}{$\begin{array}{l}\text { What are the characteristics } \\
\text { of suspected malignant } \\
\text { lesions? } \\
n=633\end{array}$} & $\mathrm{n}$ & 287 & 346 & \\
\hline & Painful and ulcerated. & $69(24.0)$ & $144(41.6)$ & $<0.001$ \\
\hline & $\begin{array}{l}\text { Painless with rigid } \\
\text { edges. }\end{array}$ & $215(74.9)$ & $179(51.7)$ & $<0.001$ \\
\hline & Fetid and purulent. & $39(13.6)$ & $37(10.7)$ & 0.272 \\
\hline \multirow{2}{*}{$\begin{array}{l}\text { Is SCC the most frequently } \\
\text { encountered type? } \\
n=605\end{array}$} & $\mathrm{n}$ & 279 & 326 & \multirow{2}{*}{$<0.001$} \\
\hline & Yes & $207(74.9)$ & $193(59.2)$ & \\
\hline Is the tongue the site that & $\mathrm{n}$ & 280 & 329 & \multirow[b]{2}{*}{0.032} \\
\hline $\begin{array}{l}\text { of SCC? } \\
n=609\end{array}$ & Yes & $109(38.9)$ & $100(30.4)$ & \\
\hline \multirow{6}{*}{$\begin{array}{l}\text { What are the initial clinical } \\
\text { signs of oral cancer? } \\
n=633\end{array}$} & $\mathrm{n}$ & 287 & 346 & \\
\hline & Abundant salivation. & $7(2.4)$ & $18(5.2)$ & 0.023 \\
\hline & Painless ulcers. & $151(52.6)$ & $105(30.4)$ & 0.001 \\
\hline & Hard nodules. & $125(43.5)$ & $135(39.0)$ & 0.140 \\
\hline & Severe pain. & $18(6.3)$ & $19(5.5)$ & 0.736 \\
\hline & Do not know. & $21(7.3)$ & $89(25.7)$ & $<0.001$ \\
\hline \multirow{6}{*}{$\begin{array}{l}\text { What are the characteristics } \\
\text { of lymph nodes of cervical } \\
\text { metastases linked to oral } \\
\text { cancer felt during palpation? } \\
n=628\end{array}$} & $\mathrm{n}$ & 284 & 344 & \\
\hline & Hard, sore and mobile. & $46(16.2)$ & $46(13.4)$ & 0.418 \\
\hline & $\begin{array}{l}\text { Hard, pain-free, and with } \\
\text { or without mobility. }\end{array}$ & $195(68.7)$ & $148(43.0)$ & 0.064 \\
\hline & Soft, sore, and mobile. & $8(2.8)$ & $20(5.8)$ & 0.006 \\
\hline & $\begin{array}{l}\text { Soft, pain-free, and with } \\
\text { or without mobility. }\end{array}$ & $7(2.5)$ & $21(6.1)$ & 0.002 \\
\hline & Do not know. & $30(10.6)$ & $116(33.7)$ & 0.037 \\
\hline
\end{tabular}

Note: Abbreviations: SCC, squamous cell carcinoma; Chi square test. Significance level of 0.05 . In each question, missing values correspond to non-response. 
The tongue was not correctly identified as the intraoral site with the highest incidence of SCC by the majority in either group, indicating a lack of knowledge about the most frequent site of SCC occurrence. With regard to the most common initial clinical observation in cases of oral cancer, most students who had studied oral medicine correctly reported that it was a painless ulcer. Moreover, most students who had studied oral medicine correctly reported that PMLs appeared as painless lesions with rigid margins. With regard to the clinical features of metastatic lymph nodes in cases of oral cancer, in both groups most students correctly reported that such lymph nodes tended to be hard, not associated with pain, and either mobile or fixed. The importance of dentists in the prevention and early diagnosis of oral cancer, and perceptions about levels of knowledge and continuing education are summarised in Table 4.

Table 4. Perception of knowledge, dentists' importance, and continuing education ( $N=646$; Paraná, Brazil).

\begin{tabular}{|c|c|c|c|c|}
\hline \multirow[b]{2}{*}{ Questions } & & \multicolumn{2}{|c|}{ Oral medicine course } & \multirow[b]{2}{*}{$\mathrm{p}$-value } \\
\hline & & $\begin{array}{c}\text { Yes } \\
\text { n (\%) }\end{array}$ & $\begin{array}{c}\text { No } \\
\text { n (\%) }\end{array}$ & \\
\hline \multirow{5}{*}{$\begin{array}{l}\text { What is the importance of } \\
\text { dentists in the prevention } \\
\text { and early diagnosis of oral } \\
\text { cancer? } \\
n=641\end{array}$} & $\mathrm{n}$ & 287 & 354 & \multirow{5}{*}{0.007} \\
\hline & High & $283(98.6)$ & $331(93.5)$ & \\
\hline & Average & $3(1.0)$ & $14(4.0)$ & \\
\hline & Low & $1(0.3)$ & $1(0.3)$ & \\
\hline & Do not know. & $0(0.0)$ & $8(2.3)$ & \\
\hline \multirow{5}{*}{$\begin{array}{l}\text { What do you perceive } \\
\text { your level of oral cancer } \\
\text { knowledge to be? } \\
n=620\end{array}$} & $\mathrm{n}$ & 275 & 345 & \multirow{5}{*}{$<0.001$} \\
\hline & Great & $3(1.1)$ & $3(0.9)$ & \\
\hline & Good & $84(30.5)$ & $38(11.0)$ & \\
\hline & Regular & $153(55.6)$ & $163(47.2)$ & \\
\hline & Insufficient & 35 (12.7) & $141(40.9)$ & \\
\hline \multirow{6}{*}{$\begin{array}{l}\text { When did you last } \\
\text { participate in continuing } \\
\text { education? } \\
n=282\end{array}$} & $n$ & 282 & $\mathrm{n} / \mathrm{a}$ & \multirow{6}{*}{$<0.001$} \\
\hline & During the past year & $92(32.6)$ & $\mathrm{n} / \mathrm{a}$ & \\
\hline & From $2-5$ years & $64(22.7)$ & $\mathrm{n} / \mathrm{a}$ & \\
\hline & Up to 5 years & $1(0.4)$ & $\mathrm{n} / \mathrm{a}$ & \\
\hline & Never & $75(26.6)$ & $\mathrm{n} / \mathrm{a}$ & \\
\hline & Do not know & $50(17.7)$ & $\mathrm{n} / \mathrm{a}$ & \\
\hline
\end{tabular}

Abbreviations: $n / a$, not applicable. Chi square test. Significance level of 0.05 . In each question, missing values correspond to non-response.

\section{Discussion}

The early detection of oral cancer is positively associated with a better prognosis, therefore it is imperative that dental students be sufficiently trained and competent in the diagnosis and multidisciplinary treatment of the disease ${ }^{4}$. A dentist's ability to identify PMLs and initial malignant lesions depends largely on the knowledge and skills they acquire during their undergraduate course ${ }^{16,17}$. In the present study undergraduate dental students' levels of knowledge about oral cancer were considered reasonable, which is consistent with previous reports ${ }^{18,19}$. The comparative appeal of 
areas of dentistry related to aesthetics, implant dentistry and prosthetic rehabilitation, which may be more profitable for clinicians, may lessen students' interest in the diagnosis of oral lesions. If this is the case, a new mentality with regard to the value of preventive oral health in the context of disease needs to be fostered.

Tobacco use and alcohol abuse have been identified as prominent aetiologies for oral cancer ${ }^{4,17-19,20}$. Both groups in the present study were aware that these two parameters are positive risk factors, but students who had studied oral medicine were more certain of these factors, which is concordant with the results of previous studies ${ }^{21,22}$.

HPV infection, sun exposure, and a previous history of oral cancer are evidently prominent risk factors for oral carcinogenesis ${ }^{18}$. Notably however, awareness of HPV infection ${ }^{4,17}$ and low fruit and vegetable intake $e^{4,17-20}$ as risk factors remains poor, even among professionals ${ }^{23}$. The two groups surveyed in the present study did not correctly identify HPV infection or low fruit and vegetable intake as risk factors. Sun exposure was also generally poorly identified, but it was identified more often by students who had studied oral medicine, which is concordant with previous studies ${ }^{17,19}$.

The consumption of hot food and beverages and spicy foods, obesity, poor oral hygiene, poor-fitting dentures, a family history of cancer, heredity, and chronic infections were not considered risk factors by the majority of students in both groups in the present study, although they have been implicated as aetiological factors for SCC 4,18,19. Thus, a substantial lack of knowledge of scientifically proven risk factors and non-risk factors was observed, as it has been in previous studies ${ }^{17,18}$.

The correct identification of PMLs is fundamental with regard to malignant oral neoplasms ${ }^{22}$. In the present study the vast majority of students who had studied oral medicine identified leucoplakia as a PML. In contrast, other equally important PMLs such as erythroplakia, lichen planus, and actinic cheilitis tended not to be identified in either group, which is concordant with a study reported by Alami et al. ${ }^{12}$ in 2013 and another reported by Jayasinghe et al. ${ }^{22}$ in 2016.

In the current study students who had studied oral medicine tended to consider painless and rigid-edged oral lesions 'suspicious lesions', and this has also been observed in similar previous studies ${ }^{12}$. Conversely, students who had not studied oral medicine often wrongly described suspicious oral lesions as painful and ulcerated, which are generally only characteristic of oral lesions when they reach an advanced stage. Inaccurate knowledge about clinical aspects of oral lesions among practitioners was also reported by Razavi et al. ${ }^{23}$ in 2013. In the present study just over half the undergraduates who had not studied oral medicine and most of those who had correctly identified SCC as the most common histological type of oral cancer, and those observations are concordant with other studies that have evaluated dental students ${ }^{22}$.

Caucasians, men and individuals aged $>40$ years have the highest incidence of SCC $^{24,25}$. In the present study students who had studied oral medicine tended to correctly identify the aged $>40$ years age group as being associated with a higher prevalence of SCC, but it was less frequently identified in the other group.

The tongue and floor of the mouth are the most common sites of oral cancer lesions 4 . In the present study the tongue tended not to be cited as a common site of SCC in 
either of the two groups surveyed. Notably, when professionals were evaluated in two previous studies this common site was identified by the majority in one ${ }^{23}$, but only a small percentage in another ${ }^{20}$. This suggests that there may be considerable variation in awareness of this parameter, even among fully qualified professionals.

In the current study students who had studied oral medicine tended to correctly report that oral cancer is initially asymptomatic. However, neither group satisfactorily identified initial signs. The signs and symptoms considered initial warnings for established oral cancer include white and red spots, localised hardening, bleeding, ulceration, necrosis, and painless fixed or mobile lymph nodes ${ }^{4}$.

Visual inspection is the most effective method for identifying oral lesions ${ }^{4}$. The majority of students in the current study reported that they performed a complete intraoral examination during the first appointment, and similar findings have been reported in previous studies ${ }^{18,20,26}$. Lymph node palpation was reportedly not performed frequently however, with students asserting that they did not know how to perform such a procedure. In the present study most students reported that they would prefer to refer a patient to a specialist for detailed diagnostic procedures, when needed. It has previously been suggested that there is a lack of adequate knowledge pertaining to oral cancer among dental professionals ${ }^{8}$, and that a protocol for the early detection of oral cancer is necessary ${ }^{27}$.

Prior to the administration of the questionnaire the respondents were specifically instructed not to guess at the correct answer to a question if they did not know it, simply for the purposes of returning a 'complete' questionnaire. Accordingly, in some cases questions were left blank by the respondents. These absent responses did not detract from the validity of the study results at all, and on the contrary they added to it by way of eliminating any potentially confounding effects resulting from lucky guesses'. It is also notable with regard to validity that only $0.93 \%$ of potential respondents abstained from the questionnaire. The study was limited by the fact that only students from two institutions were evaluated. A study conducted at a national level will assess students' knowledge about oral cancer more representatively.

The present study demonstrates a need to update undergraduate curricula in dentistry using methods that engage students' interest in preventive measures pertaining to oral lesions. It is likely that the appeal of components of modern dentistry such as aesthetic procedures, implantology and prosthetic treatments-which are associated with comparatively high financial yields-divert the interest of dentistry students away from preventive dentistry.

In conclusion, the early detection of risk factors for oral cancer via the use of effective diagnostic tools by dentists has become imperative. In the present study a higher rate of correct responses pertaining to oral cancer-related knowledge was observed in students who had studied oral medicine. There was a general lack of satisfactory identification of certain risk factors for head and neck cancer, including HPV, chronic sun exposure and nutritional deficiency. Thus, it is of fundamental importance that knowledge about oral cancer be well developed in undergraduate dental students, and that continuing education be part of the ongoing dental curricula, even after the conclusion of undergraduate training. 


\section{References}

1. Ferlay J, Soerjomataram I, Dikshit R, Eser S, Mathers C, Rebelo M, et al. Cancer incidence and mortality worldwide: sources, methods and major patterns in GLOBOCAN 2012. Int J Cancer. 2015 Mar 1;136(5):E359-86. doi: 10.1002/ijc.29210.

2. Perdomo S, Martin Roa G, Brennan P, Forman D, Sierra MS. Head and neck cancer burden and preventive measures in Central and South America. Cancer Epidemiol. 2016 Sep;44 Suppl 1:S43-S52. doi: 10.1016/j.canep.2016.03.012.

3. Bagavathula AS, Zakaria NB, Jamshed SQ. Knowledge of future dental practitioners towards oral cancer: exploratory findings from a public university in Malaysia. Int J Dent. 2015;2015:218065. doi: 10.1155/2015/218065.

4. Joseph BK, Sundaram DB, Ellepola ANB. Assessing oral cancer knowledge among undergraduate dental students in Kuwait University. J Cancer Educ. 2015 Sep;30(3):415-20. doi: 10.1007/s13187-014-0734-7.

5. Hertrampf K, Wenz HJ, Koller M, Wiltfang J. Comparing dentists' and the public's awareness about oral cancer in a community-based study in Northern Germany. J Craniomaxillofac Surg. 2012 Jan;40(1):28-32. doi: 10.1016/j.jcms.2010.11.011

6. Hertrampf K, enz HJ, Koller M, Springer I, Jargot A, Wiltfang J. Assessing dentists' knowledge about oral cancer: translation and linguistic validation of a standardized questionnaire from American English into German. Oral Oncol. 2009 Oct;45(10):877-82. doi: 10.1016/j.oraloncology.2009.02.010.

7. Elango KJ, Anandkrishnan N, Suresh A, lyer SK, Ramaiyer SK, Kuriakose MA. Mouth self-examination to improve oral cancer awareness and early detection in a high-risk population. Oral Oncol. 2011 Jul;47(7):620-4. doi: 10.1016/j.oraloncology.2011.05.001.

8. Mehdizadeh M, Majidi MS, Sadeghi S, Hamzeh M. Evaluation of knowledge, attitude and practice of general dentists regarding oral cancer in Sari, Iran. Iran J Cancer Prev. 2014 Spring;7(2):101-4.

9. Al-Maweri SA, Abbas A, Tarakji B, Al-Jamaei AS, Alaizari NA, Al-Shamiri HM. Knowledge and opinions regarding oral cancer among Yemeni dental students. Asian Pac J Cancer Prev. 2015;16(5):1765-70.

10. Andrade SN, Muniz LV, Soares JMA, Chaves ALF, Ribeiro RLMA. [Oral cancer: assessment of knowledge and conduct of dentists in primary health care]. Rev Bras Odontol. 2014;71:42-47. Portuguese.

11. Angheben PF, Salum FG, Cherubini K, Figueiredo MAZ. [Oral cancer knowledge background of dental school students of the Pontifical Catholic University of Rio Grande do Sul]. Rev Odontol Bras Central. 2013;21(60):33-40. Portuguese.

12. Alami AY, El Sabbagh RF, Hamdan A. Knowledge of oral cancer among recently graduated medical and dental professionals in Amman, Jordan. J Dent Educ. 2013 Oct;77(10):1356-64.

13. American Cancer Society. Oral Cancer; 2007. Available from: www.cancer.org.

14. Warnakulasuriya S, Johnson NW, Van Der Waal I. Nomenclature and classification of potentially malignant disorders of the oral mucosa. J Oral Pathol Med. 2007 Nov;36(10):575-80.

15. El-Naggar AK, Chan JKC, Grandis JR, Takata T, Slootweg PJ. WHO classification of head and neck tumours. In: WHO/IARC classification of tumours. $4^{\text {th }}$ ed. Lyon, France: IARC; 2017. p. 347.

16. Cerero-Lapiedra R, Esparza-Gómez GC, Casado-de la Cruz L, Domínguez-Gordillo AA, Corral-Linaza C, Seoane-Romero JM. Ability of dental students in Spain to identify potentially malignant disorders and oral cancer. J Dent Educ. 2015 Aug;79(8):959-64.

17. Frola MI, Barrios R. Knowledge and attitudes about oral cancer among dental students after Bologna Plan Implementation. J Cancer Educ. 2017 Sep;32(3):634-9. doi: 10.1007/s13187-016-0990-9. 
18. Kujan O, Alzoghaibi I, Azzeghaiby S, Altamimi MA, Tarakji B, Hanouneh S, et al. Knowledge and attitudes of Saudi dental undergraduates on oral cancer. J Cancer Educ. 2014 Dec;29(4):735-8. doi: 10.1007/s13187-014-0647-5.

19. Rahman B, Hawas N, Rahman MM, Rabah AF, Al Kawas S. Assessing dental students' knowledge of oral cancer in the United Arab Emirates. Int Dent J. 2013 Apr;63(2):80-4. doi: 10.1111/idj.12017.

20. Kebabcioğlu Ö, Pekiner FN. Assessing oral cancer awareness among dentists. J Cancer Educ. 2018 Oct;33(5):1020-1026. doi: 10.1007/s13187-017-1199-2.

21. Silva SR, Juliano Y, Novo NF, Weinfeld I. Comparative study of knowledge about oral cancer. Einstein (Sao Paulo). 2016 Jul-Sep;14(3):338-345. doi: 10.1590/S1679-45082016A03729.

22. Jayasinghe RD, Sherminie LPG, Amarasinghe H, Sitheeque MAM. Level of awareness of oral cancer and oral potentially malignant disorders among medical and dental undergraduates. Ceylon Med J. 2016 Jun;61(2):77-9. doi: 10.4038/cmj.v61i2.8289.

23. Razavi SM, Zolfaghari B, Foroohandeh M, Doost ME, Tahani B. Dentists knowledge, attitude, and practice regarding oral cancer in Iran. J Cancer Educ. 2013 Jun;28(2):335-41. doi: 10.1007/s13187-013-0460-6.

24. Garrote LF, Herrero R, Reyes RM, Vaccarella S, Anta JL, Ferbeye L, et al. Risk factors for cancer of the oral cavity and oro-pharynx in Cuba. Br J Cancer. 2001 Jul 6;85(1):46-54.

25. Udeabor SE, Rana M, Wegener G, Gellrich NC, Eckardt AM. Squamous cell carcinoma of the oral cavity and the oropharynx in patients less than 40 years of age: a 20-year analysis. Head Neck Oncol. 2012 May 30;4:28. doi: 10.1186/1758-3284-4-28.

26. Soares TRC, Carvalho MEA, Pinto LSS, Falcão CA, Matos FTC, Santos TC. Oral cancer knowledge and awareness among dental students. Braz J Oral Sci. 2014 Mar;13(1)28-33. doi: 10.1590/1677-3225v13n1a06.

27. Lehew CH, Epstein JB, Kaste LM, Choi YK. Assessing oral cancer early detection: clarifying dentists' practices. J Public Health Dent. 2010 Spring;70(2):93-100. doi: 10.1111/j.1752-7325.2009.00148.x. 